\title{
Deformation and damage due to drying-induced salt crystallization in porous limestone
}

\author{
Hannelore Derluyn ${ }^{\mathrm{a}, \mathrm{b}, *}$, Peter Moonen ${ }^{\mathrm{a}, \mathrm{b}}$, Jan Carmeliet ${ }^{\mathrm{a}, \mathrm{b}}$ \\ ${ }^{a}$ ETH Zurich, Chair of Building Physics, Wolfgang-Pauli-Strasse 15, 8093 Zürich, \\ Switzerland \\ ${ }^{b}$ EMPA, Swiss Federal Laboratories for Materials Science and Technology, Laboratory for \\ Building Science and Technology, Überlandstrasse 129, 8600 Dübendorf, Switzerland
}

\begin{abstract}
This paper presents a computational model coupling heat, water and salt ion transport, salt crystallization, deformation and damage in porous materials. We focus on crystallization-induced damage. The theory of poromechanics is employed to relate stress, induced by crystallization processes or hygro-thermal origin, to the material's mechanical response. A non-local formulation is developed to describe the crystallization kinetics. The model performance is illustrated by simulating the damage caused by sodium chloride crystallization in a porous limestone. The results are compared with experimental observations based on neutron and X-ray imaging. The simulation results suggest that the crystallization kinetics in porous materials have to be accurately understood in order to be able to control salt dam-
\end{abstract}

*Corresponding author: tel: +41 58765 4722; email: hderluyn@gmail.com;

address until 30 Sep.'13: EMPA Dübendorf, Überlandstrasse 129, 8600 Dübendorf, Switzerland

address from 1 Oct.'13: Ghent University, Department of Geology and Soil Science UGCT, Krijgslaan 281, S8, 9000 Gent, Belgium

Email addresses: hderluyn@gmail.com (Hannelore Derluyn), moonen@arch.ethz.ch, peter.moonen@empa.ch (Peter Moonen), carmeliet@arch.ethz.ch, jan.carmeliet@empa.ch (Jan Carmeliet)

Preprint submitted to Journal of the Mechanics and Physics of Solids August 20, 2013 
age. The results show that the effective stress caused by salt crystallization depends not only on the crystallization pressure but also on the amount of salt crystals, which is determined by the spreading of crystals in the porous material and the crystallization kinetics.

Keywords: salt crystallization, A. fracture, B. porous material, C. finite elements, C. nondestructive evaluation

1 1. Introduction

2 Water and dissolved salt ions may penetrate into building materials due 3 to diffusive and advective transport. Upon changes in the environmental 4 conditions, salt can crystallize at the surface (efflorescence) or inside the ma5 terial (subflorescence). Subflorescence is accompanied with the development 6 of crystallization pressures, which may lead to spalling and cracking of the 7 material, and thus to a reduction of the lifetime of a construction or mon8 ument. Until now, the mechanism of crystallization in confined conditions 9 and the related damage processes, as well as the computational modeling,

are still subject of scientific analysis. The availability of a model providing a full coupling between heat-water-salt ion transport, salt crystallization, deformations and damage would however be an important asset for engineers and conservators. It would allow them to assess and compare different maintenance, repair or conservation techniques or to assess the durability of a new building material under different climatic conditions, without having to perform long-term experiments.

Coupled numerical models for heat-water-salt transport and salt crystallization in building materials have been developed and described in the 
literature (Espinosa et al., 2007; Nicolai et al., 2007; Koniorczyk, 2012). Theories defining the crystallization pressure that is exerted when salt crystals grow in confined conditions are described as well (Scherer, 1999; Flatt, 2002; Steiger, 2005a,b; Coussy, 2006). Moonen et al. (2010, 2011) developed a model that covers the effect of thermal and hygric changes on the damage behavior of porous media. There remains however a need for bringing together the available approaches within a single unifying framework. It is especially challenging to formulate the coupling between salt crystallization and the mechanical response of the building material and to accurately model the crystallization kinetics in a physically and numerically sound way.

In the next section, we present a fully coupled model for heat, water and salt ion transport, salt crystallization, material deformation and damage in porous media. We briefly recall the modeling of heat and moisture transport (Derluyn, 2012). The modeling of the salt crystallization process, the coupling with the mechanical behavior and the damage criterion are discussed in more detail. In section 3, we summarize experimental observations of damage caused by sodium chloride crystallization, induced by drying of an initially wet limestone (Derluyn, 2012). The material and salt properties, needed as input for the model, are also given. Section 4 comprises the simulation of the performed experiment. Comparison with the experimental data suggests that the crystallization kinetics play an important role in the accurate prediction of salt damage. 


\section{A coupled model for transport, crystallization, deformation and} damage

\subsection{Conservation of mass}

We consider the porous medium consisting of a superposition of four phases: (1) the solid material matrix, (2) the gas phase, (3) the liquid phase and (4) the crystal phase. In these phases several components can be present. For the gas phase we consider dry air and water vapor, for the liquid phase water and dissolved salt ions. Exchange of water can occur between the liquid and the gas phase due to evaporation or condensation, or between the liquid and the crystal phase when hydrated salt crystals form or dissolve. Exchange of salt ions occurs between the liquid and the crystal phase when crystals precipitate or dissolve. We assume that the dissolved salt does not separate macroscopically in the absence of an electric field. Thus the cations and anions are always transported jointly.

We further assume that the solid phase does not exchange mass with other phases. We consider the gas pressure, $p_{g}$, to be constant and equal to the atmospheric pressure. In addition, we consider changes in the water vapor mass to be negligible with respect to changes in the liquid water mass and we assume that salt crystals do not move in the pore space.

Under these assumptions, the mass balance is expressed by:

$$
\Phi \frac{\partial\left(S_{l} \rho_{l}+S_{c r} \rho_{c r}\right)}{\partial t}=\nabla \cdot\left(\mathbf{K}_{l} \nabla p_{c}+\boldsymbol{\delta}_{v} \nabla p_{v}\right)
$$

with $\Phi$ the total accessible porosity, $S_{l}$ and $S_{c r}$ the liquid and the crystal saturation degree, and $\rho_{l}$ and $\rho_{c r}$ the density of the liquid phase and of the salt crystal. $\mathbf{K}_{l}$ is the liquid permeability as function of capillary pressure $p_{c}$. 
64 interface and is defined as:

$$
p_{c}=p_{l}-p_{g}
$$

with $p_{l}$ the liquid pressure and $p_{g}$ the (constant) gas pressure. $\boldsymbol{\delta}_{v}$ is the vapor permeability in function of vapor pressure $p_{v}$. The vapor pressure can be expressed in terms of the capillary pressure $p_{c}$, the absolute temperature $T$ and the water activity $a_{w}$ by the modified Kelvin relation:

$$
p_{v}=a_{w} p_{v, s a t} \exp \left(\frac{p_{c}}{\rho_{w} R_{v} T}\right)
$$

with $p_{v, s a t}$ the saturated vapor pressure, $\rho_{w}$ the water density and $R_{v}$ the gas constant for water vapor. The water activity depends on the temperature and the salt concentration and accounts for the change of the vapor pressure in equilibrium with a salt solution, compared to the vapor pressure in equilibrium with pure water. For pure water, the water activity equals 1. The higher the salt concentration gets, the lower the water activity will be, leading to lower vapor pressures.

Under the assumption that the dissolved salt ions are transported together, the mass balance for the salt dissolved in the liquid phase reads:

$$
\Phi \frac{\partial\left(S_{l} \rho_{l} C\right)}{\partial t}+\Phi \frac{\partial S_{c r} / \bar{V}_{c r}}{\partial t}=\nabla \cdot\left(\rho_{l} \mathbf{D}_{i}^{l} \nabla C\right)+\nabla \cdot\left(C \mathbf{K}_{l} \nabla p_{c}\right)
$$

with $C$ the salt concentration in mole/ $\mathrm{kg}$ liquid solution and $\bar{V}_{c r}$ the molar volume of the salt crystal. $\mathbf{D}_{i}^{l}$ is the salt diffusion coefficient in the liquid phase. 


\subsection{Conservation of energy}

The global energy balance for the porous medium reads:

$$
\begin{gathered}
\frac{\partial\left(\left((1-\Phi) c_{p, s} \rho_{s}+\Phi c_{p, l} S_{l} \rho_{l}+\Phi c_{p, c r} S_{c r} \rho_{c r}\right)\left(T-T_{0}\right)\right)}{\partial t}+ \\
\frac{\partial \Phi L_{c r} S_{c r} \rho_{c r}}{\partial t}+\nabla \cdot \mathbf{q}_{e}=0
\end{gathered}
$$

assuming that the enthalpy of water vapor and of dry air are negligible for the application of our model (Janssen, 2002). $c_{p, s}, c_{p, l}$ and $c_{p, c r}$ are the specific heat capacities at atmospheric pressure of the solid phase, the liquid phase and the crystal phase, respectively. $\rho_{s}$ is the density of the solid material matrix, $L_{c r}$ the heat of crystallization and $T_{0}$ the reference temperature for the enthalpy, being $0^{\circ} \mathrm{C}(273.15 \mathrm{~K})$.

The heat flux $\mathbf{q}_{e}$ is a combination of a conductive part and an advective part. The conductive part is given by Fourier's law:

$$
\mathbf{q}_{e, c}=-\lambda \nabla T
$$

with $\boldsymbol{\lambda}$ the apparent thermal conductivity of the porous material. The advective part is described as:

$$
\mathbf{q}_{e, a}=-\left(c_{p, v}\left(T-T_{0}\right)+L_{v}\right) \boldsymbol{\delta}_{v} \nabla p_{v}-c_{p, l}\left(T-T_{0}\right) \mathbf{K}_{l} \nabla p_{c}
$$

with $c_{p, v}$ the specific heat capacity of water vapor and $L_{v}$ the latent heat of evaporation of water.

\subsection{Salt crystallization}

The salt crystal mass balance reads:

$$
\Phi \frac{\partial\left(S_{c r} \rho_{c r}\right)}{\partial t}=e_{c r l}
$$


where we have to define the mass exchange $e_{c r l}$ between the liquid and the crystal phase. This mass exchange is described by the kinetics of salt crystallization or dissolution. It is assumed that the supersaturation $U$ is the driving force for crystallization, and consequently that the mass exchange during crystallization is given by (Espinosa et al., 2008; Koniorczyk, 2010):

$$
e_{c r l}=\zeta K_{m, c r}(U-1)^{g_{c r}} \text { for } U>U_{t h r}
$$

where $K_{m, c r}$ and $g_{c r}$ are kinetic parameters and $\zeta$ is the fraction of the capillary active pore space filled with salt solution. In order for new crystals to nucleate and grow, the supersaturation has to exceed a threshold value $U_{t h r}$.

Dissolution is described by a similar type of equation, only the kinetic parameters and the threshold value differ:

$$
e_{c r l}=-\zeta K_{m, d i s s}(1-U)^{g_{d i s s}} \text { for } U<1
$$

For the modeling of the crystallization, besides the kinetics, also the availability of pore volume space needs to be considered. If no space is available for crystals to grow, crystallization will stop and consequently the concentration in the solution will remain higher than when the crystals could grow freely. Moreover, dissolution can only take place as long as there are crystals present. Finally, the presence of crystals at a certain location influences nucleation and growth of crystals at neighboring locations. In order to get a stable numerical method incorporating all these constraints, the mass exchange term $e_{c r l}$ is implemented as:

$$
\begin{gathered}
e_{c r l}=f\left(S_{c r}, 1\right) \cdot \zeta K_{m, c r}\left(\max \left(U, U_{t h r}\right)-U_{t h r}\right)^{g_{c r}}+ \\
f\left(S_{c r}, 0\right) \cdot \zeta K_{m, d i s s}(1-\min (U, 1))^{g_{d i s s}}
\end{gathered}
$$


where the first term represents crystal growth and the second term represents crystal dissolution.

The function $f$ is introduced to ensure that:

1. Crystallization stops when the available pore volume is occupied by salt crystals: as long as $S_{c r}<1, f\left(S_{c r}, 1\right)$ equals 1 and the crystallization kinetics are active. When the pore volume is filled with crystals, $S_{c r}=1$, no crystallization occurs anymore and consequently $f\left(S_{c r}, 1\right)$ equals 0 .

2. Dissolution can occur as long as there are still crystals present: as long as $S_{c r}>0, f\left(S_{c r}, 0\right)$ equals -1 . When all crystals are dissolved and $S_{c r}=0$, the dissolution kinetics stop and $f\left(S_{c r}, 0\right)$ equals 0 .

Physically, we would only need a step function to define $f$. However, as step functions may introduce numerical problems due to their discontinuous nature, we smooth the function $f$ by means of an exponential function:

$$
f\left(x_{1}, x_{2}\right)=\operatorname{sgn}\left(x_{2}-x_{1}\right) \cdot\left(1-\exp \left(-\left|\frac{x_{1}-x_{2}}{H B W}\right|\right)\right)
$$

where $\operatorname{sgn}()$ represents the signum function, $x_{1}$ and $x_{2}$ are values, and $H B W$ is a parameter controlling the width over which the step is smeared in the function $f$. The half-band-width $H B W$ of this function is taken low $(H B W=0.01)$ in order to assure that the exponential function rapidly approaches zero as the difference $|x-r|$ increases and that the function $f$ approximates as close as possible a step function.

The function $U_{t h r}$ is defined as:

$$
U_{t h r}=1+\left(U_{\text {start }}-1\right) \cdot \exp \left(-v \bar{S}_{c r}\right)
$$

and represents the drop of the crystallization threshold from $U_{\text {start }}$ to 1 . For 
primary crystallization (i.e. if no crystals are present) the supersaturation has to exceed the supersaturation value $U_{\text {start }}$ before crystallization starts. The drop from $U_{\text {start }}$ to 1 is related to the nucleation and growth kinetics. The nucleation and growth kinetics determine how long a certain supersaturation $U$ is maintained until a sufficient amount of crystals have nucleated and/or sufficiently large crystals have grown so that new crystals start to grow at lower supersaturation levels. These phenomena are incorporated in the parameter $v$ and the function $\bar{S}_{c r} . \bar{S}_{c r}$ is a measure for the amount of crystals in the immediate neighborhood, influencing the crystallization kinetics at the location being evaluated. $v$ quantifies how important the presence of already formed crystals is on the crystallization threshold $U_{t h r}$. A non-local formulation is developed for the function $\bar{S}_{c r}$, defining $\bar{S}_{c r}$ as:

$$
\bar{S}_{c r}=\frac{\int_{\Omega} w_{f} S_{c r} \mathrm{~d} \Omega}{\int_{\Omega} w_{f} \mathrm{~d} \Omega}
$$

with $w_{f}$ a weighting function, defined as a multivariate normal distribution:

$$
w_{f}=\frac{1}{(2 \pi)^{\frac{k}{2}} l^{k}} \exp \left(-\frac{r^{2}}{2 l^{2}}\right)
$$

with $r$ the distance away from the evaluated point and $l$ the influence length. $k$ represents the number of dimensions (1, 2 or 3 ). The influence length $l$ controls the extent of the crystallization zone. The smaller the value for $l$ is, the more localized crystallization will be; larger $l$-values lead to crystallization that is more spread over the domain $\Omega$.

\subsection{Conservation of momentum}

The solid momentum balance, in absence of body forces, reads:

$$
\nabla \cdot \sigma_{s}=0
$$


with $\boldsymbol{\sigma}_{s}$ the partial stress tensor, expressed as:

$$
\boldsymbol{\sigma}_{s}=\boldsymbol{\sigma}-b p_{s} \mathbf{I}
$$

with $\boldsymbol{\sigma}$ the effective stress tensor, $b$ the Biot coefficient, $p_{s}$ the solid pressure and $\mathbf{I}$ the second order unit tensor. $p_{s}$ accounts for the mechanical effects of the constituents in the pore space on the macroscopic behavior of the porous material. The Biot coefficient is defined as:

$$
b=1-\frac{\tilde{K}}{\tilde{K}_{s}} \leq 1
$$

with $\tilde{K}$ the bulk modulus of the porous material (solid matrix and pore space) and $\tilde{K}_{s}$ the bulk modulus of the solid matrix.

The solid pressure is defined according to the theory of poromechanics (Coussy, 2004, 2010):

$$
p_{s}=\sum_{j}\left[S_{j}\left(p_{j}-p_{0, j}\right)\right]
$$

where $j$ represents the different phases present in the pore space, being gas, liquid and crystal. $p_{j}$ is the pressure exerted by phase $j$ and $p_{0, j}$ is the pressure which accounts for the averaged pressure shift induced by the interface stress, $2 \sigma_{s, j} / r$, between the phase and the solid matrix, with respect to the possible values of the pore radius $r$ (Coussy, 2010). The pressure $p_{0, j}$ is expressed as (Coussy, 2010):

$$
p_{0, j}=\frac{1}{S_{j}} \int_{0}^{\infty} \frac{2 \sigma_{s, j}}{r} \frac{\mathrm{d} S_{j}}{\mathrm{~d} r} \mathrm{~d} r
$$

It is generally assumed that there is a thin liquid film between the salt crystal and the solid matrix (see Figure 1) (Scherer, 2004; Steiger, 2005a). Thus there is no direct interface between the salt crystal and the solid matrix. Therefore, we assume that we can omit the interfacial stress between the crystal phase 


$$
p_{s}=p_{g}+\left(S_{l}+S_{c r}\right) p_{c}+S_{c r} p_{x}-S_{g} p_{0, g}-\left(S_{l}+S_{c r}\right) p_{0, l}
$$

where $p_{0, l}$ is defined as:

$$
p_{0, l}=\frac{1}{S_{l}+S_{c r}} \int_{0}^{\infty} \frac{2 \sigma_{s, l}}{r} \frac{\mathrm{d}\left(S_{l}+S_{c r}\right)}{\mathrm{d} r} \mathrm{~d} r
$$

and $p_{0, g}$ as:

$$
p_{0, g}=\frac{1}{S_{g}} \int_{0}^{\infty} \frac{2 \sigma_{s, g}}{r} \frac{\mathrm{d}\left(S_{g}\right)}{\mathrm{d} r} \mathrm{~d} r=-\frac{1}{S_{g}} \int_{0}^{\infty} \frac{2 \sigma_{s, g}}{r} \frac{\mathrm{d}\left(S_{l}+S_{c r}\right)}{\mathrm{d} r} \mathrm{~d} r
$$

Knowing that $\frac{2 \sigma_{s, l}}{r}-\frac{2 \sigma_{s, g}}{r}$ equals the capillary pressure $p_{c}$, we can write:

$$
p_{s}=p_{g}+\left(S_{l}+S_{c r}\right) p_{c}+S_{c r} p_{x}-\int_{0}^{\infty} p_{c} \frac{\mathrm{d}\left(S_{l}+S_{c r}\right)}{\mathrm{d} r} \mathrm{~d} r
$$

Starting from a reference state $p_{s}=0$ defined by $p_{g}=p_{a t m}, p_{c}=p_{c, \text { ref }}$ and $p_{x}=p_{x, r e f}$, and assuming that the gas pressure is constant and equal to the atmospheric pressure, equation 25 becomes:

$$
p_{s}=\int_{p_{c, r e f}}^{p_{c}}\left(S_{l}+S_{c r}\right) \mathrm{d} p_{c}+S_{c r}\left(p_{x}-p_{x, r e f}\right)
$$


The effective stress tensor $\boldsymbol{\sigma}$ is given by:

$$
\boldsymbol{\sigma}=\boldsymbol{D}\left(\boldsymbol{\epsilon}-\boldsymbol{\epsilon}_{T}\right)
$$

where $\boldsymbol{D}$ is the $4^{\text {th }}$ order elasticity tensor, assuming that the porous material exhibits linear elastic mechanical behavior. $\boldsymbol{\epsilon}$ is the second order strain tensor equal to the symmetric gradient of the displacement field $\mathbf{u}$ under the assumption of small deformations:

$$
\boldsymbol{\epsilon}=\nabla^{s y m} \mathbf{u}
$$

$\boldsymbol{\epsilon}_{T}$ is the thermal strain tensor, accounting for the thermal expansion or contraction of the porous material:

$$
\boldsymbol{\epsilon}_{T}=\alpha \mathbf{I}\left(T-T_{r e f}\right)
$$

with $\alpha$ the thermal expansion coefficient of the porous material and $T_{\text {ref }}$ the reference temperature.

\subsection{Damage}

We assume that damage occurs, i.e. that a crack develops, when the $j^{\text {th }}$ principal component $\sigma_{j}$ of the effective stress tensor, determined from equation 16 using definitions 17 and 27, exceeds the material strength $f_{t}^{0}$. This is expressed by the following criterion:

$$
f=\sigma_{j}-f_{t}^{0} \leqslant 0
$$

If equation 30 is violated at a material point, a crack surface develops normal to the $j^{\text {th }}$ principal stress direction. The dependence of the material strength on the liquid saturation degree $S_{l}$ is accounted for in the model (see equation $38)$. 


\section{Drying experiment, material and salt properties}

\subsection{Drying experiment}

Drying of a Savonnières limestone sample $\left(10 \times 10 \times 8.5 \mathrm{~mm}^{3}\right)$ at $45^{\circ} \mathrm{C}$, initially saturated with a 5.8 molal sodium chloride solution, has been visualized and quantified using quantitative neutron imaging analysis (Derluyn, 2012). The moisture content resolution with this technique amounts to $0.04 \mathrm{~kg} / \mathrm{m}^{3}$. The sample was prepared by applying a water and vapor tight membrane on the lateral sides (aluminum tape) in order to create a one-dimensional drying process. Drying occurred in the direction perpendicular to the bedding of Savonnières limestone. A hydrophobic treatment (SILRES BS 280, Wacker) was applied on the upper $3 \mathrm{~mm}$ of the sample. Drying could only occur through the hydrophobically treated upper part as the bottom surface was sealed. The hydrophobic treatment was intended to prevent salt efflorescence and induce in-pore crystallization. During the drying, the neutron radiographs of high spatial resolution (nominal pixel size of $13.5 \mu \mathrm{m}$ ) indicated considerable deformations after about 100 minutes. These deformations are induced by crack formation due to the crystallization of sodium chloride. The cracks resulting from the salt crystallization were characterized using X-ray micro-computed tomography. The experiment revealed that the salt crystals precipitate in the upper region of the sample, mainly in the hydrophobic zone, but below the top surface of the sample. Consequently, cracks formed in this zone (see Figure 3). 


\subsection{Savonnières properties}

The total open porosity $\Phi$ of the Savonnières limestone used for the experimental study was determined by vacuum saturation and amounts $26.9 \%$. The density of the limestone equals $1975 \mathrm{~kg} / \mathrm{m}^{3}$. During capillary saturation, only $56 \%$ of the pore space gets filled, or the capillary active porosity of untreated Savonnières limestone amounts $\Phi_{\text {unt }}=14.9 \%$. The other pores are only active in the over-capillary regime (Carmeliet and Roels, 2002). When a hydrophobic treatment is applied, the treatment occupies a fraction of the pore space, defined by the porosity $\Phi_{h}$. The capillary active pore space reduces to $\Phi_{\text {unt }}-\Phi_{h}$. The porosity affected by the hydrophobic treatment, $\Phi_{h}$, at a certain position $x$ is found by:

$$
\Phi_{h}(x)=\Phi_{u n t}-\frac{w_{l, c a p}(x)}{\rho_{l}}
$$

with $w_{l, c a p}(x)$ the capillary moisture content at the position $x$, determined from the moisture profile in the capillary saturated sample in the absence of salt crystals. As soon as salt crystals start precipitating, they as well reduce the capillary active pore space. The crystals occupy a fraction of the pore space $\Phi_{c r}=\Phi S_{c r}$ and the capillary active pore space reduces to $\Phi_{\text {unt }}-\Phi_{h}-\Phi_{c r}$.

The moisture retention curve of untreated Savonnières limestone, describing the liquid saturation degree $S_{l, u n t}$ in function of capillary pressure, is approximated by a sum of power functions (van Genuchten, 1980; Durner, 1994):

$$
S_{l, \text { unt }}\left(p_{\mathrm{c}}\right)=\sum_{j=1}^{s} l_{j}\left(1+\left(c_{j} p_{\mathrm{c}}\right)^{n_{j}}\right)^{m_{j}}
$$


with $s$ the number of pore systems, $l_{j}$ weight factors, and $c_{j}, n_{j}$ and $m_{j}$ model parameters. Parameter $m_{j}$ can be estimated as (van Genuchten, 1980):

$$
m_{j}=\frac{1-n_{j}}{n_{j}}
$$

For the wetting moisture retention curve in the capillary regime, the parameters are given in Table 1 . When the capillary active porosity is reduced by a hydrophobic treatment and/or the presence of salt crystals, the liquid saturation degree $S_{l}$ is reduced in a simplified way by multiplying $S_{l, \text { unt }}$ with the factor $1-\frac{\Phi_{h}}{\Phi_{u n t}}-\frac{\Phi_{c r}}{\Phi_{u n t}}$ (Derluyn, 2012).

The liquid permeability for pure water $K_{w, \text { unt }}$ of Savonnières limestone in function of capillary pressure was determined from the moisture profiles obtained by neutron imaging during a capillary uptake test, as explained in Derluyn et al. (2013). The liquid permeability for a salt solution $K_{l, u n t}$ can be calculated from the liquid permeability of pure water as:

$$
K_{l, \text { unt }}=K_{w, \text { unt }} \frac{\eta_{w}}{\rho_{w}} \frac{\rho_{l}}{\eta_{l}}
$$

where $\eta$ is the viscosity. The viscosity of sodium chloride solutions with a concentration between 0 to 6 molal in a temperature range of 20 to $150^{\circ} \mathrm{C}$ is given in Kestin et al. (1981). The density, as function of temperature and concentration, can be calculated following Steiger (2000, 2008). The relation expressed by equation 34 was confirmed experimentally by Derluyn et al. (2013). When the capillary active pore space is reduced by a hydrophobic treatment and/or the presence of salt crystals, the liquid permeability $K_{l}$ is reduced, similar to the liquid saturation degree, by multiplying $K_{l, u n t}$ with the factor $1-\frac{\Phi_{h}}{\Phi_{u n t}}-\frac{\Phi_{c r}}{\Phi_{u n t}}$ (Derluyn, 2012). 
The vapor permeability $\delta_{v}$ was measured with the 'cup method' following EN ISO 12572:2001 (CEN, 2001). The nonlinear vapor permeability can be described in function of the vapor pressure $p_{v}$ as:

$$
\delta_{v}=\delta_{v, a i r} \cdot\left(a+b \exp \left(c \cdot \frac{p_{v}}{p_{v, s a t}}\right)\right)
$$

with $a, b$ and $c$ parameters. The vapor permeability in air $\delta_{v \text {,air }}$ is given by Schirmer's equation (Schirmer, 1938; Ochs et al., 2008). For flow perpendicular to the bedding direction of the limestone, the parameters $a, b$ and $c$ amount $0.0109,8.86 \times 10^{-6}$ and 8.55 , respectively.

The thermal conductivity $\lambda$ was measured using the heat flow meter method (EN 1946-3:1999, SIA (1999)). An average thermal conductivity of $0.99 \mathrm{~W} / \mathrm{mK}$ was found for dry Savonnières limestone. To incorporate the influence of moisture, the thermal conductivity of water $\lambda_{w}$, multiplied with the volume fraction of water, is added to the dry thermal conductivity:

$$
\lambda\left(S_{l}\right)=\lambda_{d r y}+\lambda_{w} \Phi S_{l}
$$

Values for $\lambda_{w}$ are given by Haynes and Lide (2012), e.g. at $20^{\circ} \mathrm{C} \lambda_{w}$ equals $0.6 \mathrm{~W} / \mathrm{mK}$. The thermal capacity $c_{p, s}$ of Savonnières limestone is estimated to be $900 \mathrm{~J} / \mathrm{kgK}$ (www.engineeringtoolbox.com). The thermal expansion coefficient $\alpha$ was determined by measuring the thermal dilation in a dynamic mechanical analyser (DMA 7e, Perkin Elmer) during a heating-cooling cycle $\left(125^{\circ} \mathrm{C}-25^{\circ} \mathrm{C}\right)$, an average value of $5.5 \mu \mathrm{m} / \mathrm{mK}$ was obtained.

The E-modulus was measured on samples of $16 \mathrm{~cm}$ height and $4 \mathrm{x} 4 \mathrm{~cm}^{2}$ cross section. The samples were subjected to a compressive load up to $1 / 3^{\text {rd }}$ of their compressive strength. During this compression the deformation was measured using a strain gauge, and the E-modulus was determined from 
the load-deformation curve. In the dry state, an average E-modulus of 13.9 GPa is found perpendicular to the bedding direction. When the stone is capillary saturated, the E-modulus perpendicular to the bedding direction reduces to $11.2 \mathrm{GPa}$. The change of E-modulus with saturation degree can be approximated by:

$$
E\left(S_{l}\right)=E_{\text {wet }}+\left(E_{d r y}-E_{\text {wet }}\right) \exp \left(-p \frac{\Phi}{\Phi_{\text {unt }}} S_{l}\right)
$$

with $p$ a parameter, determined from experiments. We adopt a value of 36 (Poupeleer, 2007), but remark that this value was determined on calcium silicate board. The function in equation 37 expresses that the E-modulus decreases rapidly to the E-modulus of the wet state when the stone becomes wet $\left(S_{l}>0\right)$. The same behavior was, for example, observed by Van Den Abeele et al. (2002) on Meule sandstone.

The tensile strength of dry Savonnières limestone was determined from a tensile test. In the direction perpendicular to the bedding, the tensile strength $f_{t_{d r y}}^{0}$ equals $1.8 \mathrm{MPa}$. The tensile strength of the bulk material in function of liquid saturation degree can be written as:

$$
f_{t}^{0}\left(S_{l}\right)=\frac{f_{t_{d r y}}^{0}}{E_{d r y}} E\left(S_{l}\right)
$$

assuming the same tensile strain in dry and wet conditions.

The Biot coefficient of Savonnières limestone was not measured experimentally, but estimated from literature data of a similar limestone (Lion et al., 2004). A value of 0.77 is assumed. 


\subsection{Sodium chloride properties}

The sodium chloride diffusion coefficient in the porous material, $\mathbf{D}_{i}^{l}$, is defined by Buchwald (2000) as:

$$
\mathbf{D}_{i}^{l}=\boldsymbol{\tau}^{-1} D(C, T) \Phi S_{l}^{n}
$$

where $D(C, T)$ is the diffusion coefficient in function of concentration and temperature in a non-dilute solution, taken from Rard and Miller (1979), $\boldsymbol{\tau}$ is the tortuosity of the porous material, being 24.4 perpendicular to the bedding direction, and $n$ is the saturation exponent, taken equal to 1.6 (Buchwald, 2000).

To estimate the heat of crystallization $L_{c r}$, the method described by Marliacy et al. (2000) is adopted, as described by Derluyn (2012). The heat capacity $c_{p, c r}$ of sodium chloride crystals is obtained from Haynes and Lide (2012).

The supersaturation $U$ and the water activity $a_{w}$ are calculated using the Pitzer ion interaction approach as described by Steiger et al. (2008), thus accounting for the non-ideal behavior of pore solutions. The supersaturation and the water activity are both function of the temperature and the salt concentration. The crystallization pressure $p_{x}$ is then given by (Steiger, 2005a):

$$
p_{x}=\frac{R T}{\bar{V}_{c r}} \ln U
$$

with $R$ the universal gas constant, $T$ the absolute temperature and $\bar{V}_{c r}$ the molar volume of the crystal, being $27 \mathrm{~cm}^{3} /$ mole for sodium chloride.

The kinetic growth parameters $K_{m, c r}$ and $g_{c r}$ for sodium chloride equal $0.41 \mathrm{~kg} / \mathrm{m}^{3} \mathrm{~s}$ (Espinosa-Marzal, 2009) and 1, respectively. 


\section{Simulation results and discussion}

In this section, we simulate the coupled heat-moisture-salt transport and salt crystallization and predict the risk for salt damage for the experiment described in section 3.1. Hence, we solve equations 1, 4, 5, 8 and 16 and check when the damage criterion (equation 30) is violated. The equations are solved using the finite element method to obtain the variation of the primary variables $p_{c}, C, T, S_{c r}$ and $\mathbf{u}$ in space and time. In order to obtain a mass and energy conservative system of equations, a mixed form of the capacitive terms is used, as described in Janssen et al. (2007). A staggered solution scheme is used and each equation is solved implicitly using the Newton-Raphson method. Numerical integration is performed by means of a Gauss-Lobatto scheme. This has a similar accuracy as the more commonly used GaussLegendre scheme, but suppresses oscillations in the solution field for our set of highly non-linear PDE's.

\subsection{Input, initial and boundary conditions}

The physical properties of Savonnières limestone and sodium chloride as given in sections 3.2 and 3.3 are used. The parameters $v, l$ and $U_{\text {start }}$ in the $U_{t h r}$-function (equation 13), which are related to the crystallization kinetics, are the only parameters that cannot be determined from literature or experiments. Therefore, the sensitivity of the results with respect to these three parameters is assessed by conducting a parameter study. We perform the simulation using an $U_{\text {start }}$-value of 1.5 or 2 , a $l$-value of $1 \times 10^{-4}$ or $1 \times 10^{-3}$ $\mathrm{m}$ and a $v$-value of $10 \frac{\Phi}{\Phi_{u n t}}, 100 \frac{\Phi}{\Phi_{u n t}}$ or $1000 \frac{\Phi}{\Phi_{u n t}}$, resulting in 12 different cases. The $U_{\text {start }}$-value of 1.5 corresponds to a concentration increase of $9 \%$ by mass 
with respect to the saturated concentration at $45^{\circ} \mathrm{C}$ (based on Steiger et al. (2008)). This value is close to the maximal value of $10 \%$ mentioned by Flatt (2002).

The simulation is performed on a 1-dimensional mesh of length $L$, where $L$ equals the height of the sample used in the drying experiment, being 8.19 $\mathrm{mm}$. We acknowledge that the simulation does not completely represent the 3-dimensional nature of the sample. However, the drying process itself, inducing the crystallization damage, can be considered to be mainly 1-dimensional. As such, the crystallization and mechanical analysis can, in a first approximation, be regarded as 1-dimensional. The mesh consists of 100 equidistant elements. The same time step is used for all discretized equations. The time step is in the order of 1 to $5 \mathrm{~ms}$, assuring convergence of the coupled system of equations.

The initial capillary pressure at time $t=0$ equals $-100 \mathrm{~Pa}$ for every position in the sample, corresponding to the capillary saturated state. The initial temperature of the sample is equal to $45^{\circ} \mathrm{C}$. The initial concentration at every position in the sample equals 5.8 molal. In the initial state, no crystals are present in the sample.

The environment surrounding the sample during the experiment is characterized by a relative humidity $R H_{\text {env }}$ of $5 \%$ and a temperature $T_{e n v}$ of $45^{\circ} \mathrm{C}$. Boundary conditions of the Neumann type are imposed on the top surface of the sample, being:

$$
\begin{aligned}
\bar{q}_{m} & =C M T C\left(p_{v, e n v}-p_{v, \text { surf }}\right) \text { with } p_{v, e n v}=p_{v, s a t}\left(T_{e n v}\right) \cdot R H_{e n v} \\
\bar{q}_{e} & =H T C\left(T_{e n v}-T_{\text {surf }}\right)+\left(c_{p, v}\left(T_{\text {surf }}-T_{0}\right)+L_{v}\right) \cdot \bar{q}_{m}
\end{aligned}
$$

with $\bar{q}_{m}$ the moisture flux and $\bar{q}_{e}$ the heat flux at the boundary. $p_{v, \text { surf }}$ and 
$T_{\text {surf }}$ are the vapor pressure and the temperature at the boundary surface. The convective mass transfer coefficient $C M T C$ is determined based on inverse modeling (Derluyn, 2012) and amounts $3.95 \times 10^{-9} \mathrm{~s} / \mathrm{m}$. The convective heat transfer coefficient $C H T C$ is then given by the Chilton-Colburn analogy (Chilton and Colburn, 1934) and amounts $0.57 \mathrm{~W} / \mathrm{m}^{2} \mathrm{~K}$. The radiative heat transfer coefficient $R H T C$ is $5.1 \mathrm{~W} / \mathrm{m}^{2} \mathrm{~K}$ (CEN, 2004) and the corresponding total heat transfer coefficient $H T C$ is thus $5.67 \mathrm{~W} / \mathrm{m}^{2} \mathrm{~K}$. Zero-flux boundary conditions are applied on the bottom side of the sample.

\subsection{Results and discussion}

From the experimental results, we know that the sample starts to deform considerably after 100 minutes, due to crack formation. We expect that the effective stress at a certain position in the sample exceeds the tensile strength around this time. With this assumption, we consider the material to mechanically behave homogeneously; and we remark that this approximation does not explicitly account for the existence of local weak spots in the microstructure of the stone. An overview of the maximal effective stress reached after 2.5 hours of drying is given in Table 2 using different values for the parameters $U_{\text {start }}, l$ and $v$. Only four of the twelve sets of parameters predict damage within the simulated time frame. The table indicates that the more crystals can spread within the sample (larger $l$ value) and the faster the $U_{t h r}$-function reduces to 1 (larger $v$ value), the longer it takes before the effective stress exceeds the tensile strength.

We will further discuss three simulation results more in detail. We select the $U_{\text {start }}$-value of 1.5 , which is the closest to the maximal value expected by Flatt (2002). We compare the simulation result using $l=1 \times 10^{-4}$ and 
$v=100$, that results in damage after 114 minutes, with the simulation results using $l=1 \times 10^{-4}$ and $v=1000$ and using $l=1 \times 10^{-3}$ and $v=100$, which do not yield damage within the considered time period. The comparison is done for the first 114 minutes of the simulation. The parameter set with $l=1 \times 10^{-4}$ and $v=100$ gives the best agreement with the experimental result, whereas the other two parameter sets show the influence of different crystallization kinetics. The $U_{\text {start }}$-value of 1.5 is reached after 23 minutes. The effective stress and the strain evolution with time are given by the profiles in Figure 2. We observe that the highest stresses (Figure 2a) and strains (Figure 2d) develop at about $0.4 \mathrm{~mm}$ from the top of the sample. This is in agreement with the observed crack pattern in the sample. A vertical slice obtained from the X-ray tomographic dataset of the sample after the drying experiment is shown in Figure 3. A crack developed at the same position as where the effective stress reaches the tensile strength of $1.58 \mathrm{MPa}$.

The effective stresses in Figures $2 \mathrm{a}, 2 \mathrm{~b}$ and $2 \mathrm{c}$ are directly related to the crystal saturation degree $S_{c r}$ and the crystallization pressure $p_{x}$. It is the product of these two quantities that determines the effective stress, as expressed by equation 26. The profiles of $S_{c r}$ and $p_{x}$ are given in Figure 4. In the simulation with $l=1 \times 10^{-4}$ and $v=100$, the highest amount of crystals is reached locally (Figure 4a), and the crystallization zone in the sample is small. When changing the $v$-value to 1000 , the maximal $S_{c r}-$ value reduces and the crystals are a little more spread (Figure 4b). When changing the $l$-value to $1 \times 10^{-3}$ there is significantly more spreading of crystals, and the maximal $S_{c r}$-value consequently reduces further (Figure 4c). The crystallization pressure is related to the concentration evolution, 
given in Figures 5a, 5b and 5c. The concentration, and consequently the crystallization pressure, increase due to the drying process, and decrease due to the salt crystallization. The concentration in Figure 5b decreases faster in the crystallization zone than in Figure $5 \mathrm{a}$ due to the larger value for the parameter $v$, and thus a faster decrease of the $U_{t h r}$-value. The concentration in Figure 5c also decreases faster due to the larger parameter $l$, representing a larger influence length, and thus a larger crystallization zone. The moisture content profiles of the different simulations (Figures $5 \mathrm{~d}, 5 \mathrm{e}$ and $5 \mathrm{f}$ ) do not show a large difference. The difference is mainly in the upper part of the sample, where the crystals precipitate as indicated by the gray arrow in the figures.

As our sample can deform freely, the solid stress $\boldsymbol{\sigma}_{s}$ equals zero (i.e. is equal to the external mechanical stress). This means that the effective stress $\boldsymbol{\sigma}$ is only determined by the solid pressure $p_{s}$. Using equation 26 and considering that our simulation is 1-dimensional, so that we can denote the stresses by a scalar (i.e. we describe the stress along the height of the sample), gives:

$$
\begin{aligned}
\sigma & =b\left(\int_{-100}^{p_{c}}\left(S_{l}+S_{c r}\right) \mathrm{d} p_{c}+S_{c r} p_{x}\right) \\
& =b\left(\int_{-100}^{p_{c}}\left(S_{l, \text { unt }}\left(1-\frac{\Phi_{h}}{\Phi_{\text {unt }}}\right)\right) \mathrm{d} p_{c}+S_{c r} p_{x}\right)
\end{aligned}
$$

The effect of the hygric stresses, expressed by the first term in equation 43 is found to be negligible in this simulation, as they only range in the order of magnitude of $1000 \mathrm{~Pa}$. Thus the effective stress, given in Figures 2a, 2b, $2 \mathrm{c}$ is approximately given by:

$$
\sigma \approx b S_{c r} p_{x}
$$


The strains in Figures 2d, 2e and $2 \mathrm{f}$ are related to the crystal formation and to the temperature change in the sample. The sample cools down due to evaporative cooling as represented for the boundary location, $x=L$, in Figure 6. At other positions in the sample, the temperature evolution is similar. The cooling causes a shrinkage of the sample. As the sample can deform freely and the cooling is uniform over the sample, the strains due to the cooling are uniform and no internal stresses develop due to the thermal shrinkage. When crystals start to form, they cause expansion of the sample in the zone where the crystals precipitate.

The liquid weight decrease is given in Figure 7a. The three simulations approach the experimentally obtained data. The accumulated crystal mass is given in Figure 7b. An important observation is that the case where damage is induced after 114 minutes (simulation 1 with $l=1 \times 10^{-4}$ and $v=100$ ) corresponds to the case where the lowest amount of accumulated crystal mass is found. This indicates that the risk for salt damage depends strongly on the crystallization kinetics, rather than on the amount of crystals formed. The parameter study indicates that when it is more difficult for the crystals to form (the lower $l$ and the lower $v$ ), the damage will occur faster once crystals start to grow. This is because higher crystallization pressures can build up and the crystals precipitate more localized, causing higher effective stresses locally. This result shows the importance of the nucleation and growth kinetics for the correct prediction of salt damage risks. It indicates that if you can control the kinetics of crystallization, you can control salt damage. 


\section{Conclusions}

We have developed a fully coupled computational model that describes heat, water and ion transport, salt crystallization and deformations and damage induced by hygro-thermal and crystallization stresses. The model predicts the macroscopic behavior and physical degradation of porous materials. The model has been discussed with the focus on the prediction of salt damage caused by the formation of sodium chloride crystals in a porous limestone during drying. The simulation results show a good agreement with experimental data, obtained from neutron and X-ray imaging techniques, when choosing suitable parameters for the crystallization kinetics. These parameters are estimated based on a sensitivity study. The simulations show that the effective stresses resulting from salt crystallization do not only depend on the crystallization pressure, which is related to the supersaturation, but also on the amount of salt crystals forming and the localization of these crystals. In order to include the last aspect, a non-local formulation was incorporated in the model. Future research could focus on experimental and/or modeling studies for the reliable prediction of the kinetic parameters. The results presented in this paper suggest that controlling the nucleation and growth

kinetics is the key factor to control crystallization damage in porous building materials.

\section{Acknowledgments}

The Department of Architecture at ETH Zurich is acknowledged for cofunding the research of Hannelore Derluyn. 


\section{Vitae}

\subsection{Dr. ir. Hannelore Derluyn}

Hannelore Derluyn received her master degree in civil engineering from K.U. Leuven (Belgium) in July 2006, magna cum laude. Subsequently, she was a research affiliate at K.U. Leuven. She started her PhD studies there in January 2008 and pursued her research at ETH Zurich (Switzerland). She obtained her PhD degree from ETH Zurich in November 2012 and was awarded the ETH Medal. During her PhD studies, she was an academic guest at EMPA Dübendorf (Switzerland), Princeton University (USA) and Ghent University (Belgium). She was a postdoc at ETH Zurich/EMPA Dübendorf. From October 2013, she is an FWO-postdoc fellow at Ghent University.

\subsection{Dr. ir. Peter Moonen}

Peter Moonen studied civil engineering at K.U. Leuven (Belgium), and graduated in July 2003 with summa cum laude. After graduation, he started working on an interdisciplinary project, which resulted in a dual $\mathrm{PhD}$ degree, issued by both the K.U. Leuven and the Delft University of Technology (The Netherlands). In 2009-2010, he had the opportunity to do a postdoc at the ETH Zurich (Switzerland). Since the beginning of 2011, he is research scientist at Empa Dübendorf (Switzerland) and lecturer at ETH Zurich.

\subsection{Prof. dr. ir. Jan Carmeliet}

Since June 2008, Jan Carmeliet is full professor at the Chair of Building Physics at ETH Zurich and head of the Laboratory of Building Science and Technology of EMPA Dübendorf (Switzerland). Jan Carmeliet received his 
PhD in Civil Engineering at K.U. Leuven (Belgium) in 1992 and was a postdoctoral fellow at the Delft University of Technology (The Netherlands). He has been Assistant (1998), Associate (2001) and Full Professor (2004) at K.U. Leuven and part-time Professor at the Eindhoven University of Technology (since 2001). In 2007 he was on sabbatical leave at the University of Illinois at Urbana Champaign and at Los Alamos Governmental Laboratories.

\section{References}

Buchwald, A., 2000. Determination of the ion diffusion coefficient in moisture and salt loaded masonry materials by impedance spectroscopy, in: 3rd International PhD Symposium, Vol. 2., 10-13 October 2000, Vienna, Austria, pp. 475-482.

Carmeliet, J., Roels, S., 2002. Determination of the Moisture Capacity of Porous Building Materials. J. Build. Phys. 25 (3), 209-237.

CEN, 2001. EN ISO 12572:2001 Hygrothermal performance of building materials and products - Determination of water vapour transmission properties.

CEN, 2004. prEN 15026 Hygrothermal performance of building components and building elements - Assessment of moisture transfer by numerical simulation.

Chilton, T., Colburn, A. P., 1934. Mass transfer (absorption) coefficients. Prediction from data on heat transfer and fluid friction. Ind. Eng. Chem. 26 (11), 1183-1187. 
Coussy, O., 2004. Poromechanics, John Wiley \& Sons Ltd., Chichester, UK.

Coussy, O., 2006. Deformation and stress from in-pore drying-induced crystallization of salt. J. Mech. Phys. Solids 54 (8), 1517-1547.

Coussy, O., 2010. Mechanics and Physics of Porous Solids, first ed. John Wiley \& Sons Ltd., Chichester, UK.

Derluyn, H., 2012. Salt transport and crystallization in porous limestone: neutron - X-ray imaging and poromechanical modeling, Diss. ETH No. 20673. Ph.D. thesis, ETH Zurich, Switzerland.

Derluyn, H., Griffa, M., Mannes, D., Jerjen, I., Dewanckele, J., Vontobel, P., Sheppard, A., Derome, D., Cnudde, V., Lehmann, E., Carmeliet, J., 2013. Characterizing saline uptake and salt crystal distributions in porous limestone with neutron radiography and X-ray micro-tomography. J. Build. Phys. 36 (4), 353-374.

Durner, W., 1994. Hydraulic conductivity estimation for soils with heterogeneous pore structure. Water Resour. Res. 30 (2), 211-223.

Espinosa, R. M., Franke, L., Deckelmann, G., Gunstmann, C., 2007. Gekoppelter Wärme- und Stofftransport einschließlich der Korrosionsprozesse in porösen Baustoffen mit dem Simulationsprogramm AStra. Bauphysik 29 (3), 187-193.

Espinosa, R. M., Franke, L., Deckelmann, G., 2008. Phase changes of salts in porous materials: Crystallization, hydration and deliquescence. Constr. Build. Mater. 22 (8), 1758-1773. 
Espinosa-Marzal, R. M., 2009. Personal communication.

Flatt, R. J., 2002. Salt damage in porous materials: how high supersaturations are generated. J. Cryst. Growth 242 (3-4), 435-454.

Haynes, W., Lide, D. (Eds.), 2012. CRC Handbook of Chemistry and Physics, 92nd ed. Internet Version 2012.

Janssen, H., 2002. The influence of soil moisture transfer on building heat loss via the ground. Ph.D. thesis, K.U. Leuven, Belgium.

Janssen, H., Blocken, B., Carmeliet, J., 2007. Conservative modelling of the moisture and heat transfer in building components under atmospheric excitation. Int. J. Heat Mass Tran. 50 (5-6), 1128-1140.

Kestin, J., Ezzat Khalifa, H., Correia, R. J., 1981. Tables of the dynamic and kinematic viscosity of aqueous $\mathrm{NaCl}$ solutions in the temperature range 20$150^{\circ} \mathrm{C}$ and the pressure range 0.1-35 MPa. J. Phys. Chem. Ref. Data 10 (1), $71-87$.

Koniorczyk, M., 2010. Modelling the phase change of salt dissolved in pore water - Equilibrium and non-equilibrium approach. Constr. Build. Mater. 24 (7), 1119-1128.

Koniorczyk, M., 2012. Salt transport and crystallization in non-isothermal, partially saturated porous materials considering ions interaction model. Int. J. Heat Mass Tran. 55 (4), 665-679.

Lion, M., Skoczylas, F., Ledésert, B., 2004. Determination of the main hy- 
draulic and poro-elastic properties of a limestone from Bourgogne, France. Int. J. Rock Mech. Min. 41 (6), 915-925.

Marliacy, P., Solimando, R., Bouroukba, M., Schuffenecker, L., 2000. Thermodynamics of crystallization of sodium sulfate decahydrate in $\mathrm{H} 2 \mathrm{O}-\mathrm{NaCl}-$ Na2SO4: application to $\mathrm{Na} 2 \mathrm{SO} 4.10 \mathrm{H} 2 \mathrm{O}$-based latent heat storage materials. Thermochim. Acta 344, 85-94.

Moonen, P., Sluys, L. J., Carmeliet, J., 2010. A continuous-discontinuous approach to simulate physical degradation processes in porous media. Int. J. Numer. Meth. Eng. 84, 1009-1037.

Moonen, P., Sluys, L. J., Carmeliet, J., 2011. A continuous-discontinuous approach to simulate heat transfer in fractured media. Transport Porous Med. 89 (3), 399-419.

Nicolai, A., Grunewald, J., Zhang, J. S., 2007. Salztransport und Phasenumwandlung - Modellierung und numerische Lösung im Simulationsprogramm Delphin 5. Bauphysik 29 (3), 231-239.

Ochs, F., Heidemann, W., Mullersteinhagen, H., 2008. Effective thermal conductivity of moistened insulation materials as a function of temperature. Int. J. Heat Mass Tran. 51 (3-4), 539-552.

Poupeleer, A., 2007. Transport and crystallization of dissolved salts in cracked porous building materials. Ph.D. thesis, K.U. Leuven, Belgium.

Rard, J. A., Miller, D. G., 1979. The mutual diffusion coefficients of NaCl$\mathrm{H} 2 \mathrm{O}$ and $\mathrm{CaCl} 2-\mathrm{H} 2 \mathrm{O}$ at $25^{\circ} \mathrm{C}$ from Rayleigh interferometry. J. Solution Chem. 8 (10), 701-716. 
Scherer, G. W., 1999. Crystallization in pores. Cement Concrete Comp. 29, $1347-1358$.

Scherer, G. W., 2004. Stress from crystallization of salt. Cement Concrete Res. 34, 1613-1624.

Schirmer, R., 1938. Die Diffusionszahl von Wasserdampf-Luftgemischen und die Verdampfungs-geschwindigkeit. ZVDI Beheift Verfahrenstechnik 6, 170 .

SIA, 1999. EN 1946-3:1999 Wärmetechnisches Verhalten von Bauprodukten und Bauteilen - Technische Kriterien zur Begutachtung von Laboratorien bei der Durchführung der Messungen von Wärmeübertragungseigenschaften - Teil 3: Messung nach dem Verfahren mit dem Wärmestrom.

Steiger, M., 2000. Chapter 6: Total volumes of crystalline solids and salt solutions, in: Price, C. (Ed.), An expert chemical model for determining the environmental conditions needed to prevent salt damage in porous materials, pp. 53-63.

Steiger, M., 2005a. Crystal growth in porous materials - I: The crystallization pressure of large crystals. J. Cryst. Growth 282 (3-4), 455-469.

Steiger, M., 2005b. Crystal growth in porous materials - II: Influence of crystal size on the crystallization pressure. J. Cryst. Growth 282 (3-4), 470-481.

Steiger, M., 2008. Personal communication. 
612

613

614

Steiger, M., Kiekbusch, J., Nicolai, A., 2008. An improved model incorporating Pitzer's equations for calculation of thermodynamic properties of pore solutions implemented into an efficient program code. Constr. Build. Mater. 22 (8), 1841-1850.

Van Den Abeele, K. E.-A., Carmeliet, J., Johnson, P. A., Zinszner, B., 2002. Influence of water saturation on the nonlinear elastic mesoscopic response in Earth materials and the implications to the mechanism of nonlinearity. J. Geophys. Res. 107, 2121.

van Genuchten, M. T., 1980. A closed-form equation for predicting the hydraulic conductivity of unsaturated soils. Soil Sci. Soc. Am. J. 44, 892-898. 


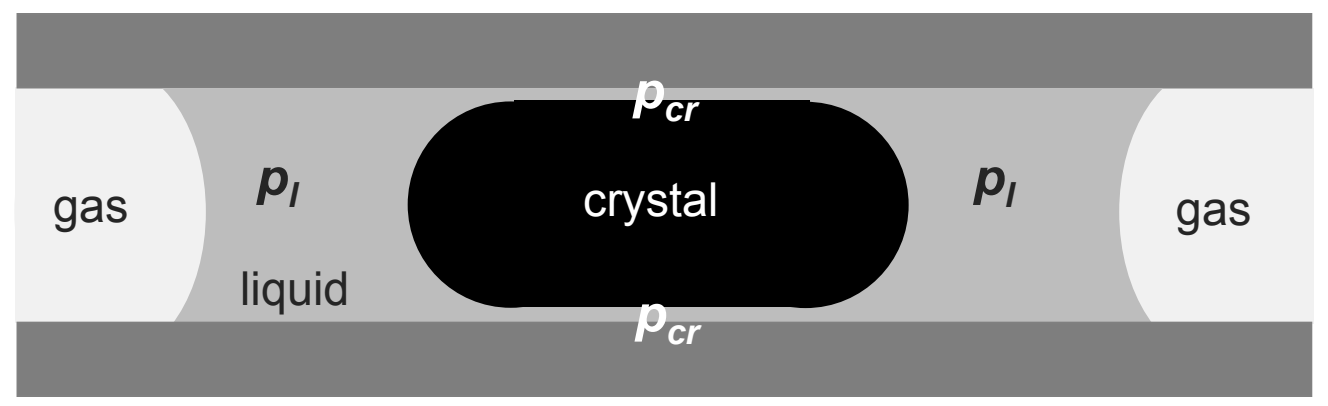

Figure 1: Schematic illustration of a crystal in a pore. A liquid film is maintained between the crystal surface and the pore wall.

Table 1: Parameters for the analytical fit of the capillary water retention curve.

\begin{tabular}{cccc}
\hline$i$ & 1 & 2 & 3 \\
\hline$c_{i}$ & $8.0 \times 10^{-7}$ & $7.0 \times 10^{-6}$ & $1.3 \times 10^{-4}$ \\
$n_{i}$ & 4.27 & 1.98 & 1.85 \\
$l_{i}$ & 0.135 & 0.256 & 0.165 \\
\hline
\end{tabular}


Table 2: Maximal principal effective stress $\sigma_{I, \max }$ after 2.5 hours using different parameter values, the height at which this effective stress is reached in the sample, and the time at which cracking occurs if the principal effective stress exceeds the tensile strength. The '-' symbol indicates that no cracks formed during the first 2.5 hours. The simulations indicated in bold are discussed further in detail.

\begin{tabular}{cccccc}
\hline$U_{\text {start }}$ & $l$ & $v$ & $\sigma_{I, \max }$ & height & time to crack \\
& $\mathrm{m}$ & & $\mathrm{MPa}$ & $\mathrm{mm}$ & min. \\
\hline 1.5 & $1 \times 10^{-3}$ & 10 & 1.03 & 7.78 & - \\
$\mathbf{1 . 5}$ & $\mathbf{1} \times \mathbf{1 0}^{-\mathbf{3}}$ & $\mathbf{1 0 0}$ & $\mathbf{0 . 4 2}$ & $\mathbf{7 . 8 6}$ & - \\
1.5 & $1 \times 10^{-3}$ & 1000 & 0.41 & 7.86 & - \\
1.5 & $1 \times 10^{-4}$ & 10 & $>f_{t}^{0}$ & 7.86 & 89 \\
$\mathbf{1 . 5}$ & $\mathbf{1} \times \mathbf{1 0}^{-\mathbf{4}}$ & $\mathbf{1 0 0}$ & $>f_{\boldsymbol{t}}^{\mathbf{0}}$ & $\mathbf{7 . 7 8}$ & $\mathbf{1 1 4}$ \\
$\mathbf{1 . 5}$ & $\mathbf{1} \times \mathbf{1 0}^{-\mathbf{4}}$ & $\mathbf{1 0 0 0}$ & $\mathbf{1 . 0 6}$ & $\mathbf{7 . 6 2}$ & - \\
\hline 2.0 & $1 \times 10^{-3}$ & 10 & 1.48 & 7.86 & - \\
2.0 & $1 \times 10^{-3}$ & 100 & 0.31 & 7.86 & - \\
2.0 & $1 \times 10^{-3}$ & 1000 & 0.28 & 7.86 & - \\
2.0 & $1 \times 10^{-4}$ & 10 & $>f_{t}^{0}$ & 7.86 & 113 \\
2.0 & $1 \times 10^{-4}$ & 100 & $>f_{t}^{0}$ & 7.86 & 115 \\
2.0 & $1 \times 10^{-4}$ & 1000 & 0.95 & 7.62 & - \\
\hline
\end{tabular}


(a)

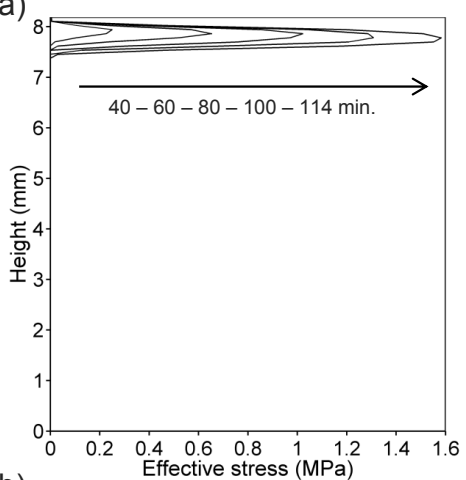

(b)

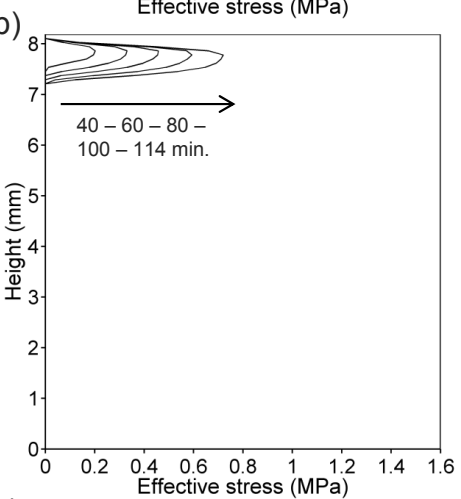

(c)

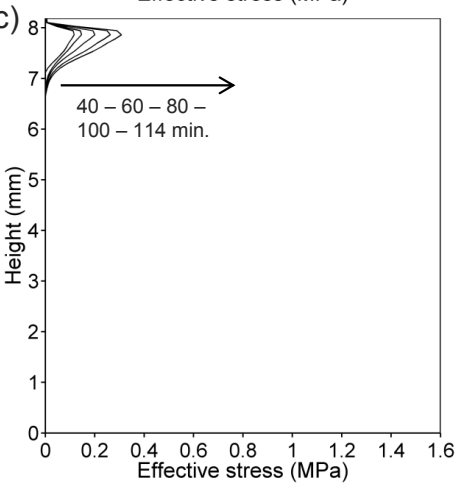

(d)
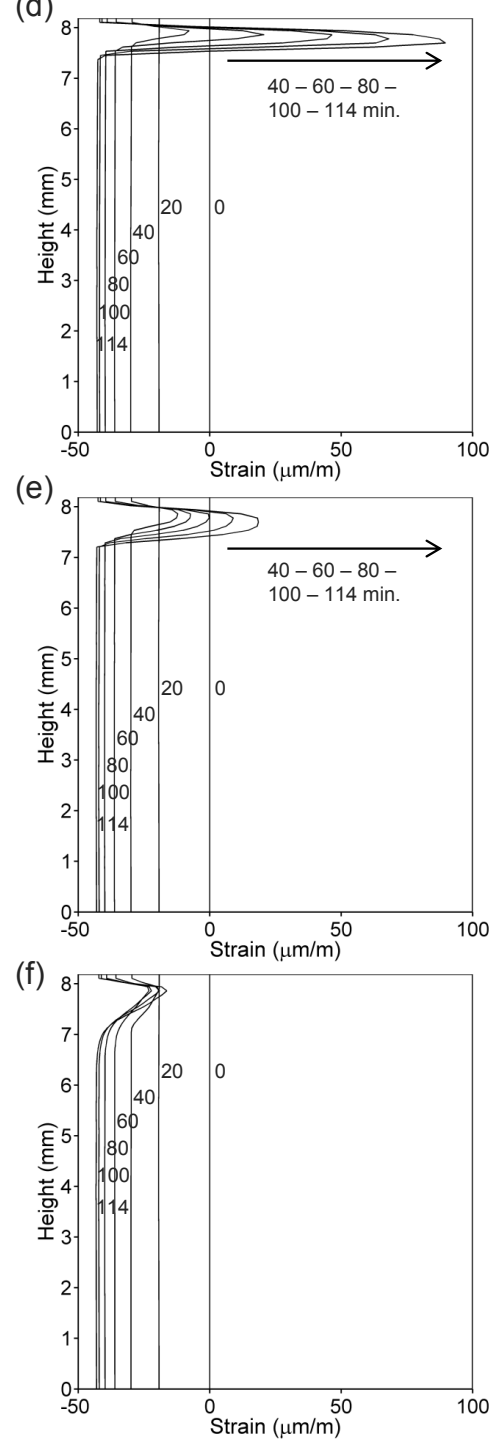

Figure 2: Effective stress (a-b-c) and strain (d-e-f) over the height of the sample for different model parameters: (a)\&(d) $l=10^{-4}, v=100$, (b)\&(e) $l=10^{-4}, v=1000,(\mathrm{c}) \&(\mathrm{f}) l=10^{-3}, v=100$. Crystallization starts after 23 minutes. 

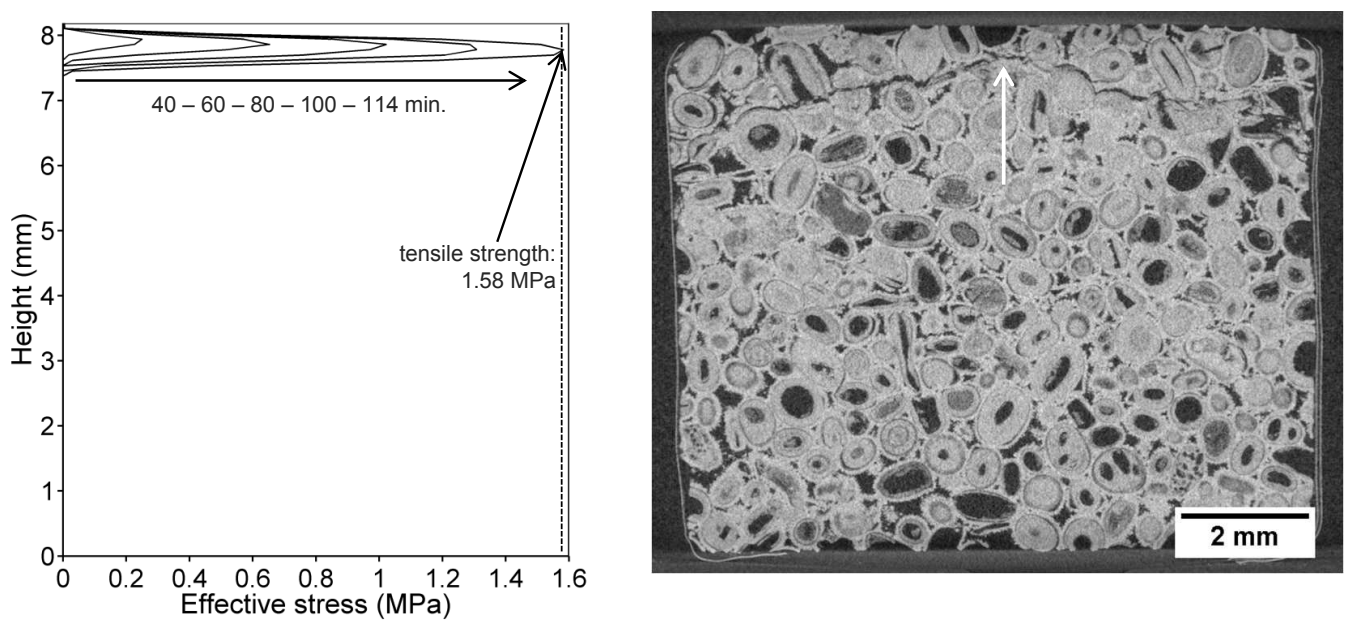

Figure 3: Comparison between the effective stress evolution, simulated with $l=10^{-4}, v=100$ (Figure $2 \mathrm{a}$ ) and the crack pattern in the sample visualized with X-ray micro-tomography. A crack is observed at the position where the maximal effective stress develops in the simulation. 
(a)

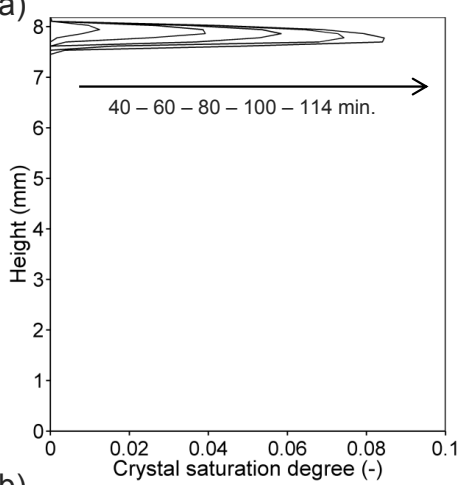

(b)
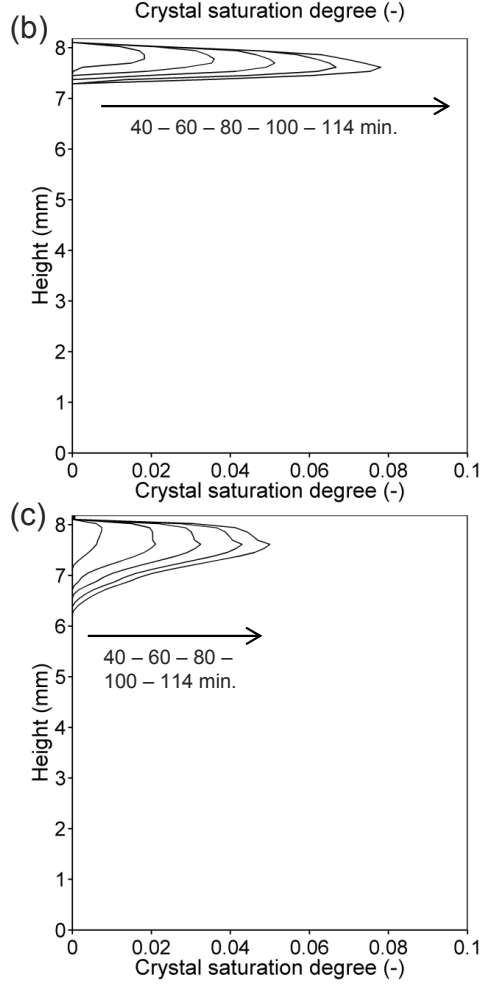

(d)
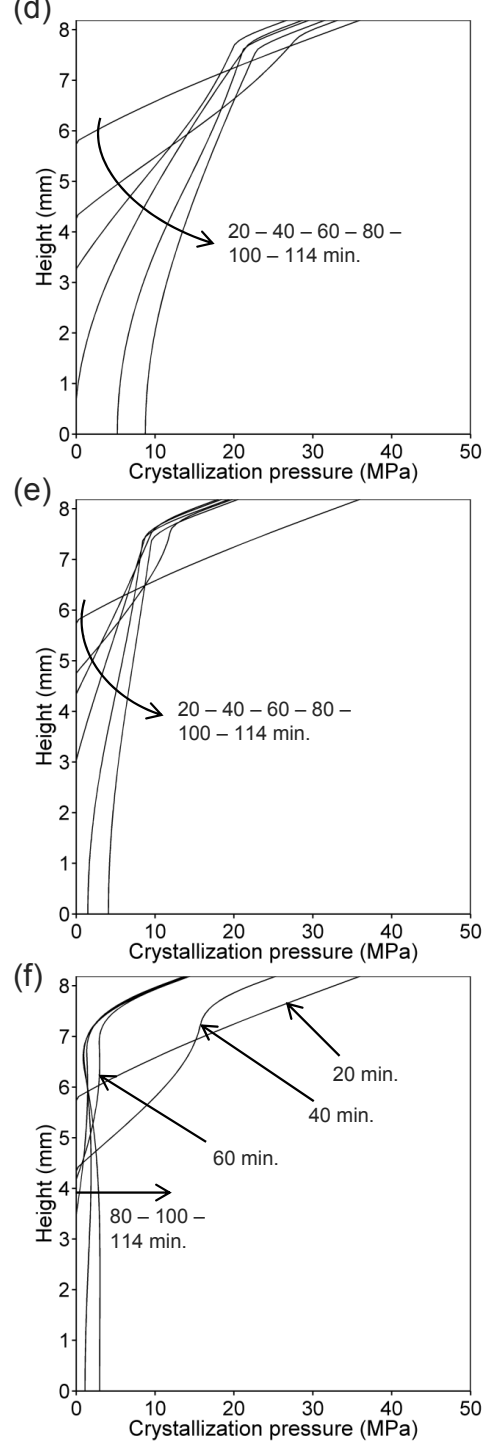

Figure 4: Salt crystallization degree (a-b-c) and crystallization pressure (de-f) over the height of the sample with different model parameters: (a)\&(d) $l=10^{-4}, v=100,(\mathrm{~b}) \&(\mathrm{e}) l=10^{-4}, v=1000,(\mathrm{c}) \&(\mathrm{f}) l=10^{-3}, v=100$. Crystallization starts after 23 minutes. 

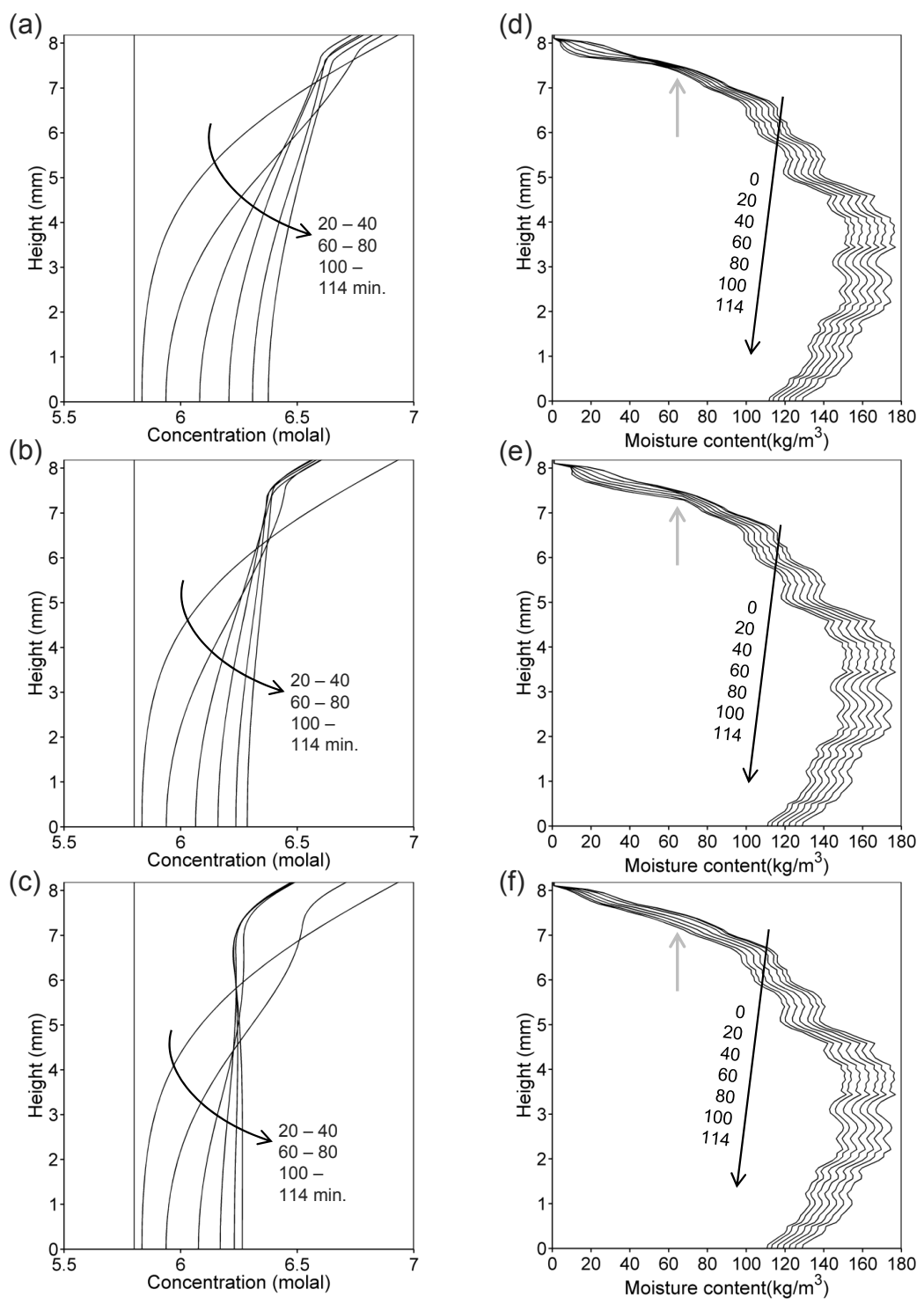

Figure 5: Salt concentration (a-b-c) and moisture content (d-e-f) over the height of the sample with different model parameters: (a) $\&(\mathrm{~d}) l=10^{-4}, v=$ 100, (b)\&(e) $l=10^{-4}, v=1000$, (c)\&(f) $l=10^{-3}, v=100$. Crystallization starts after 23 minutes. The gray arrows in figures d-e-f indicate where the main difference in the moisture profiles can be observed. 


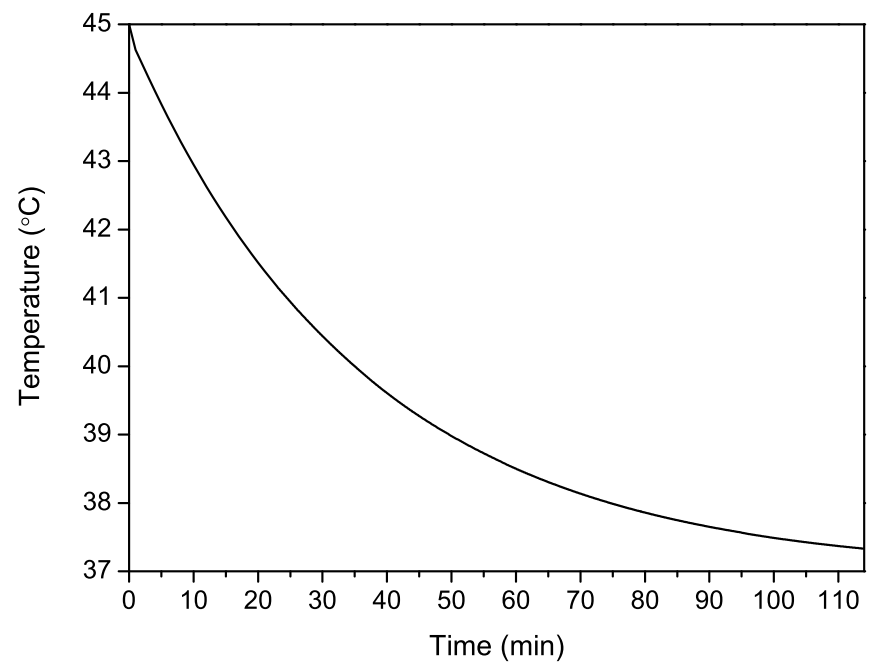

Figure 6: Temperature evolution at the boundary $x=L$ during drying. At other locations in the sample, the temperature evolution is similar. 


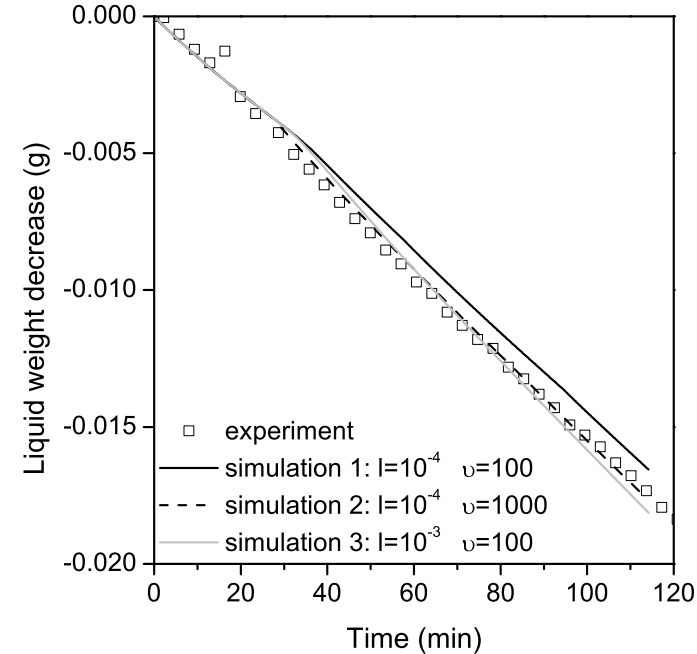

(a)

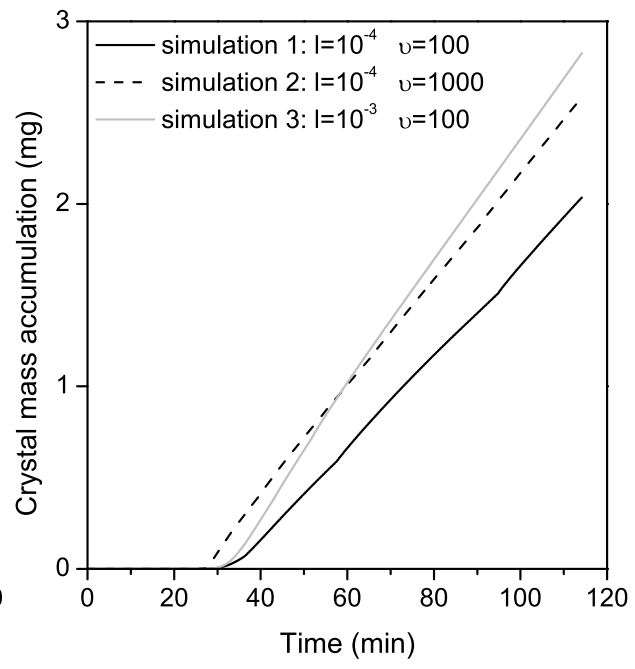

(b)

Figure 7: (a) Weight decrease and (b) salt accumulation in the sample using different model parameters for nucleation: (1) $l=10^{-4}, v=100$, (2) $l=10^{-4}$, $v=1000,(3) l=10^{-3}, v=100$. 